\title{
Systematic review on HIV situation in Addis Ababa, Ethiopia
}

\author{
Melaku Adal(D
}

\begin{abstract}
Background: HIV prevalence in the Addis Ababa is still higher in key and priority populations. Therefore, this systematic review was carried out aiming in determining the prevalence of HIV and predisposing risk factors, identification of hotspot areas, key and priority populations, availability and utilization of services, and challenges and gaps to be addressed for prevention and control of HIV epidemic in Addis Ababa.

Methods: The documents relevant to address the objectives were collected from online databases Google scholar and PubMed for published works. In addition, unpublished survey and surveillance reports, performance reports and project assessment findings, and mapping results were collected from partner organizations working on HIV/ AIDS prevention and control.

Results: It appears that the HIV prevalence stabilizes, but varies along areas and socio-demographic groups. The most common hot spots in Addis Ababa are areas where bars, groceries, pensions, guest houses, hotels, brothels, massage houses, khat houses, shisha houses, night clubs, drinking establishments and tourist frequented settings are concentrated. The recognized key population (KP) is the female sex workers (FSWs). There is sexual mixing of key and priority populations (KPPs) with the general population. There are various behavioural, biological and socioeconomic predisposing risk factors that drive HIV epidemic, and respective behavioural, biomedical and structural intervention measures are identified in the presence of gaps and challenges to address the problem.

Conclusions: HIV prevalence in Addis Ababa seems stabilized. However, it varies along different groups of the population. There are many behavioural, biological and socio-economic factors that predisposed to HIV/AIDS. Weak monitoring of the quality of interventions, limited linkage of positive clients, lost to follow up, financial shortage, limited man-power and coordination, data quality and gaps in use of program data or research findings are some of the gaps and challenges. Therefore, prevention and control measures using behavioural, structural and biomedical interventions through filling of gaps and tackle challenges should be strengthened in order to prevent and control HIV transmission.
\end{abstract}

Keywords: HIV/AIDS, Hotspot, Predisposing factors, Interventions

\section{Background}

According to HIV related estimates and projections for Ethiopia [1], there are 610,335 people living with HIV (PLHIV) with estimated adult HIV prevalence being $0.96 \%$. The Ethiopian demographic and health survey (EDHS) 2016 report [2] shows Gambella region (4.8\%) and Addis Ababa (3.4\%) to have the highest HIV prevalence rates while Somali $(<0.1 \%)$, and Southern Nations, Nationalities and peoples (SNNP, 0.4\%) regional states

Correspondence: melakuadal@gmail.com

Microbial, Cellular and Molecular Biology Department, Addis Ababa University, Addis Ababa, Ethiopia have the lowest. The adult (15-59) HIV prevalence in Ethiopia is $0.9 \%$, with varying burden by sex, age, and other demographic characteristics, across sub-regions and population groups. The urban HIV prevalence $(2.9 \%)$ is seven times higher than the prevalence in rural settings $(0.4 \%)$, women (1.2\%) having twice higher HIV prevalence than men $(0.6 \%)$ [2].

The Ethiopian population based HIV impact assessment (EPHIA) [3] showed that prevalence of HIV is $3.0 \%$ in urban settings [3]. This relatively high prevalence of HIV in Addis Ababa initiated us to look into the magnitude of the HIV prevalence, who and why they

(c) The Author(s). 2019 Open Access This article is distributed under the terms of the Creative Commons Attribution 4.0 International License (http://creativecommons.org/licenses/by/4.0/), which permits unrestricted use, distribution, and 
are affected, the availability and utilization of services for the most affected groups, and the gaps and challenges to address the problem. Therefore, this systematic review was carried out aiming in determining the prevalence of HIV (1), predisposing risk factors (2), identification of hotspot areas (3), key and priority populations (4), availability and utilization of services, and challenges and gaps to be addressed for prevention and control (5) of HIV epidemic in Addis Ababa.

\section{Methods}

\section{Protocol and registration}

This study has been designed and reported according to the Preferred Reporting Items for Systematic Reviews and Meta-Analysis (PRISMA) tool [4]. Analytic methods and inclusion criteria were specified and documented in advance.

\section{Eligibility criteria}

Studies carried out including Addis Ababa as study site from 2005 to April 2019, written in English and address HIV prevalence; predisposing behavioural, biological and socio-demographic risk factors; identified hotspot areas; identifications of most-at-risk populations (MARPS) such as key and priority populations; and intervention strategies such as behavioural, biomedical and structural intervention strategies and availability of services; and identifying gaps that could be challenges and opportunities for prevention and control of HIV/AIDS were included and analyzed following the above category.

\section{Information sources}

The documents relevant to be reviewed to address Addis Ababa were collected from online databases Google scholar and Pubmed for published work. In addition to published works, unpublished survey and surveillance reports, performance reports and project assessment findings, and mapping results were collected from Federal Ministry of Health (FMOH), Ethiopian Public Institute (EPHI), Ethiopian Public Health Association (EPHA), Organization for Social Services, Health and Development (OSSHD), Federal HIV/AIDS Prevention and Control Office (FHAPCO), Addis Ababa HIV/AIDS prevention and Control Office (AAHAPCO), Addis Ababa Health Bureau (AAHB), Population Services International/Ethiopia (PSI/E), American Centre for Disease Control and Prevention (CDC) and World Health Organization (WHO).

\section{Search}

The following terms and phrases were used as needed: HIV, AIDS, prevalence, highly active antiretroviral therapy, HAART, antiretroviral therapy, ART, compliance, adherence, resistance, predisposing factors, behavioural, biological, socioeconomic, most-at-risk populations (MARPs), khat, alcohol, drug use, knowledge, attitude, practice, KAP, and behavioural change; condom use, abstinence, faithfulness, stigma, discrimination, HIV counseling and testing, HCT, voluntary counseling and testing, VCT, prevention of mother to child transmission and PMTCT.

\section{Study selection, data collection and items}

A total of 241 documents were collected, among which only 109 of them were relevant and used for the quick review. The quick review form was developed to collect all necessary information of the source document with full citation, main findings, and to match to specific objectives. After quick review, 41 documents with relevant information were selected and used. Quantitative data were collected from surveys and performance reports. Based on a closer and in-depth review of quantitative data, the raw information was categorized under exclusive thematic areas based on the specific objectives in order to make the data presentation easier (Fig. 1). Furthermore, the quantitative methods were applied in synthesizing of secondary data and present it in tables and graphs.

\section{Synthesis of results}

The qualitative information are presented as in Table 1 and described in text. In addition, the quantitative information is summarized in Table 2 and Figs. 2, 3, 4, 5, 6.

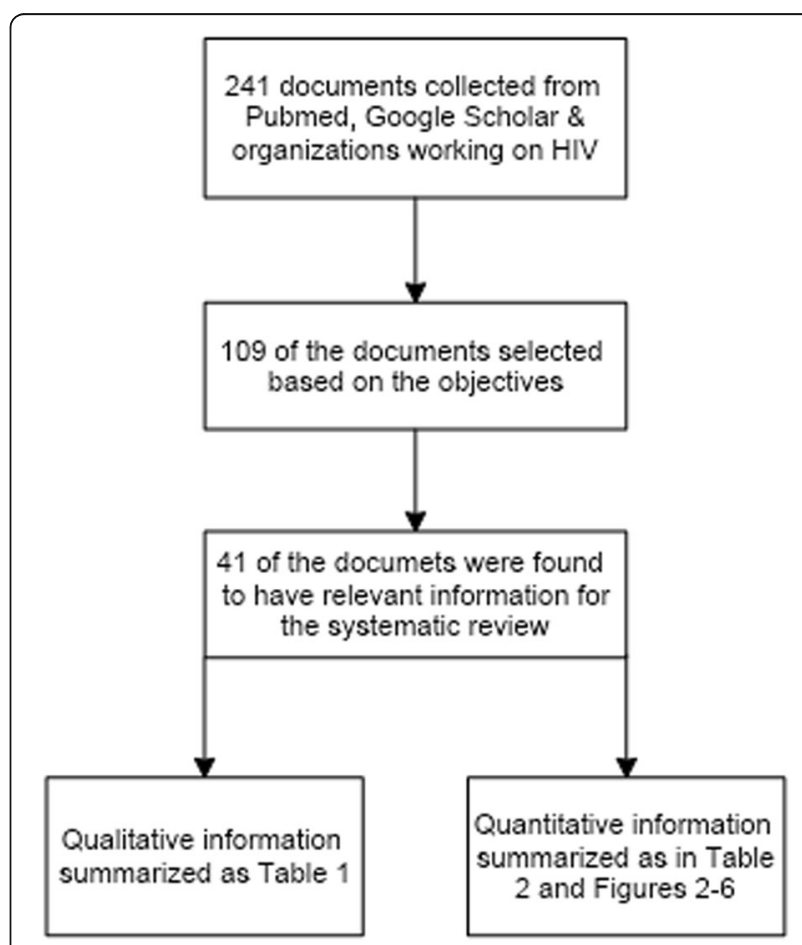

Fig. 1 The flow chart used for collection of qualitative and quantitative data 
Table 1 Summary information about the source materials used

\begin{tabular}{|c|c|c|c|c|}
\hline No. & Documents & Type of document & Key findings & Objectives \\
\hline 1 & EPHI, 2018a & Report & - HIV prevalence Table 2 and Figure 1 & 1 \\
\hline 2 & CSA and ICF, 2016 & Survey & $\begin{array}{l}\text { - HIV prevalence } 3.4 \% \text { in Addis Ababa } \\
\text { - Men who had sex with non-cohabiting partners is highest in } \\
\text { Addis Ababa (26\%) than the national average }(16 \%) \\
\text { - The mean number of lifetime sexual partners reported by men } \\
\text { in Addis Ababa (5.2\%) } \\
\text { - Women reported using a condom during last sexual intercourse } \\
\text { with non-regular partners } 41.8 \% \text { and men } 72.4 \% \\
\text { - Discordant couples (4.3\%) }\end{array}$ & 1,3 \\
\hline 3 & EPHI, 2018b & Survey & $\begin{array}{l}\text { - HIV prevalence is } 3.1 \% \text { in Addis Ababa } \\
\text { - VLS of whole country in urban areas is } 70.1 \% \text { (Female } 71.7 \% \text { and } \\
\text { Male } 66.8 \% \text { ), varies by age, sex, and region, } \\
\text { - Status of the three } 90^{\prime} \text { s in Addis Ababa: } 65.2 \% \text { for the } 1^{\text {st }} 90,63.3 \% \\
\text { for the } 2^{\text {nd }} 90 \text { and } 58.2 \% \text { of all PLHIV }\end{array}$ & 1,5 \\
\hline 4 & Moher et al., 2015 & Article & • PRISMA Statement & - \\
\hline 5 & CSA and ORC, 2005 & Survey & - HIV prevalence is $4.7 \%$ in Addis Ababa & 1,3 \\
\hline 6 & CSA and ICF, 2011 & Survey & - HIV prevalence is $5.2 \%$ in Addis Ababa & 1,3 \\
\hline 7 & EPHI, 2015 & Report & - Figure 1 for HIV prevalence & 1 \\
\hline 8 & EPHI, 2011 & Report & - Figure 1 for HIV prevalence & 1 \\
\hline 9 & EPHI, 2014 & Report & - Figure 1 for HIV prevalence & 1 \\
\hline 10 & EPHI, 2017 & Report & - Figure 1 for HIV prevalence & 1 \\
\hline 11 & FHAPCO, 2018 & Report & $\begin{array}{l}\text { - Behavioural, biomedical and structural interventions } \\
\text { - ART coverage is } 74.6 \% \text {; viral load testing coverage } ~ 60 \% \text { with } 87.5 \% \text { VLS } \\
\text { - In Addis Ababa, the total number on ART were } 94,240 \text { and 3,616 were } \\
\text { newly enrolled; retention at } 12 \text { months } 87 \% \\
\text { - Figures } 2,3,4\end{array}$ & 1,5 \\
\hline 12 & EPHA/CDC (2012) & Report & - Death related to HIV/AIDS in Figure 5 & 1 \\
\hline 13 & AAHAPCO, 2017 & Synthesis & $\begin{array}{l}\text { - Key drivers of the epidemic; hotspot areas; intervention strategies; } \\
\text { challenges on intervention }\end{array}$ & $2,3,4,5$ \\
\hline 14 & Lakew et.al., 2015 & Article & - $5.7 \%$ HIV-positives among mobile workers & 1,4 \\
\hline 15 & FMOE, 2012 & Survey & $\begin{array}{l}\text { - low level of knowledge, peer pressure, practices of unsafe sex, the } \\
\text { proliferation of addictions (shisha, khat, alcohol) and substance abuse, } \\
\text { gender-based violence were driving forces for the spread of the epidemic. }\end{array}$ & $3,4,5$ \\
\hline 16 & $\mathrm{PSI} / \mathrm{E}_{,}$ & Research brief & $\begin{array}{l}\text { - Non-self-identified (NSI) FSWs to supplement their income to support } \\
\text { family or the desire for fashion and luxury goods } \\
\text { - The main barrier to condom use is higher payment, in addition to } \\
\text { intimacy and trust with long-term clients } \\
\text { - NSI FSWs felt some polices favor clients and they would be unlikely to } \\
\text { get a positive outcome by reporting violence } \\
\text { - NSI FSWs may be more likely to experience violence, but less likely to } \\
\text { report it given the hidden nature of their work }\end{array}$ & 3 \\
\hline 17 & Deyessa et al., 2018 & Survey & $\begin{array}{l}\text { - Male users dominated female users at a ratio of 9:1; } 3 / 4 \text { of the IDUs were } \\
\text { below the age of } 35 \text { years } \\
\text { - The estimated IDUs in Addis Ababa were 4,068 } \\
\text { - The majority, } 200 \text { ( } 72.5 \% \text { ) of the drug users from Addis Ababa had the } \\
\text { habit of reusing needle and syringe } \\
\text { - Of the } 177 \text { Addis Ababa residents who claimed to have tested for } \\
\text { HIV, } 70(39.5 \%) \text { disclosed as HIV positive }\end{array}$ & $1,3,4$ \\
\hline 18 & Cherie et al., 2012 & Article & $\begin{array}{l}\text { - Peer pressure is the most important factor associated with risky sexual } \\
\text { behavior among school adolescents }\end{array}$ & 3 \\
\hline 19 & Mirkuzie (2018) & Article & $\begin{array}{l}\cdot 2 \% \text { and } 4 \% \text { of the HIV exposed babies were HIV positive by } 6 \text { and } \\
18 \text { months, respectively } \\
\text { - No prophylactic ART and mixed feeding were predictors for having an } \\
\text { HIV positive antibody test at } 18 \text { months }\end{array}$ & 5 \\
\hline 20 & Klaus et al., 2015 & Article & $\begin{array}{l}\text { - The barriers to PMTCT completion: hopelessness and carelessness, lack } \\
\text { of understanding of the efficacy of ARV, and negative religious influences. }\end{array}$ & 3 \\
\hline 21 & Endalamaw et al., 2018 & Article & - Rural residence, home delivery, no ART prophylaxis and mixed feeding & 3 \\
\hline
\end{tabular}


Table 1 Summary information about the source materials used (Continued)

\begin{tabular}{|c|c|c|}
\hline No. & Documents & Type of document \\
\hline 22 & Menna et al., 2014 & Article \\
\hline 23 & EPHA et al., 2013 & Report \\
\hline 24 & UNODC, 2014 & Survey \\
\hline 25 & PEPFAR, 2018 & Strategic Plan \\
\hline 26 & $P S I / E, 2016$ & Research brief \\
\hline 27 & Demissie et al., 2018 & Article \\
\hline 28 & FHAPCO, 2018 & National roadmap \\
\hline 29 & $\mathrm{FMoH}, 2018$ & Report \\
\hline 30 & Biadgilign et al., 2011 & Article \\
\hline 31 & Gesesew et al., 2016 & Article \\
\hline
\end{tabular}

increased the risk of HIV transmission

- High knowledge of HIV/AIDS, attitude towards 'ABC' rules, being tested for HIV and chewing khat are factors associated with multiple sexual partnerships among secondary school students.

- The estimated HIV prevalence among FSWs in towns was $23.0 \%$; $4.5 \%$ in truck drivers

- 15.5\% of drivers have misconceptions about HIV prevention methods

- $21 \%$ of drivers accept that once they had unprotected sex with someone, there is no reason to use condoms

- Divorced/Separated/Widowed have also high HIV prevalence

- HIV prevalence $4.2 \%$ in prison settings

- There are about 200,000 FSWs in Ethiopia

- The majority of FSWs (57.5 \%) are 24 years and younger, and about $14 \%$ are 19 years or younger

- $>6 \%$ of HIV positive FSWs who started ART reported discontinuation of treatment for more than seven days in the three months prior to the assessment

- The prevalence of HIV among IDUs was $6 \%$

- $40 \%$ of IDUs reported ever sharing needles; $56 \%$ reported sharing other Objectives injecting equipment; among HIV-positive IDUs, $60 \%$ reported sharing a needle the last time they injected.

- Most of the IDUs were males (96\%) with a mean age of 26 years.

- Key and priority populations

- Behavioural, biomedical and structural interventions

- Parents refusing to give consent for their children to access HIV testing services (HTS) and ART services

- Males being away from home, drug addiction, fear of stigma \& discrimination, distance from ART clinics, dependent on food supplies, mental problems, HIV negative partners; and baseline CD4 $<200$ cells $/ \mathrm{mm} 3$ and WHO clinical stages $3 \& 4$ were factors of ART discontinuation.

- Being rural dweller, illiteracy, marriage, alcohol use, smoking, having mental illness and being bed ridden functional status, having HIV positive partner and being co-infected with TB/HIV were factors for ART discontinuation.

- ART discontinued adults were more likely to be females, tuberculosis/HIV co-infected, with immunological failure and no history of HIV testing.

- Economic constraints, perceived stigma \& discrimination, medication side effects, and dissatisfaction with healthcare services, disclosure of HIV status, social support, responsibility for raising children, improved health on ART, and receiving education and counseling were factors for patients being non-adherent and lost to follow-up

- With the introduction of appointment spacing, some patients complain of lack of storage space for the six-month supply of ARTs, poor storage conditions for their medicines, and preference of frequent follow up. Health workers are also concerned about adherence given the less frequent contact of PLHIV with the health services

- Key and priority populations

- HIV transmission interventions include behavioural, biomedical and structural components.

- The plan intends to achieve the three 90 targets by 2020 through targeted social mobilization and HIV testing, linkage to care, quality of HIV treatment, and virtual elimination of MTCT, envisioning ending AIDS by 2030

- Combination ART acheives sustained HIV viral suppression and contributes to improvement in the quality of life; and reductions in mortality, progression to AIDS, opportunistic infections (Ols), hospitalization, and decreased HIV transmission to uninfected persons 
Table 1 Summary information about the source materials used (Continued)

\begin{tabular}{|c|c|c|c|c|}
\hline No. & Documents & Type of document & Key findings & Objectives \\
\hline 39 & Misgena, 2011 & Article & $\begin{array}{l}\text { - Challenges related to HAART include lifelong therapy, failed treatment } \\
\text { response, optimal time to start treatment and switching regimens, } \\
\text { drug interaction, toxicity, cardiovascular risks, drug resistance, lost to } \\
\text { follow-up, immune reconstitution inflammatory syndrome (IRIS), early } \\
\text { mortality, challenges in viral load testing. }\end{array}$ & 5 \\
\hline 40 & Bernabas et al., 2017 & Article & $\begin{array}{l}\text { - Noncompliance to medical instruction and poor adherence fosters } \\
\text { emergence of drug resistance. Limited availability of laboratory } \\
\text { services such as HIV RNA load and drug resistance testing and } \\
\text { monitoring due to lack of experience of health professionals, and } \\
\text { weak infrastructure and health care system contribute to delay in } \\
\text { diagnosis of treatment failure }\end{array}$ & 5 \\
\hline 41 & Telele et al., 2018 & Article & $\begin{array}{l}\text { - The high rate of transmitted and preexisting drug resistance mutations } \\
\text { in Ethiopian patients are identified }\end{array}$ & 5 \\
\hline
\end{tabular}

Note: Objective representation of the agreed thematic areas, 1 = Determine the prevalence and incidence of HIV and mortality rate in the City; 2 = Identify the hot spot areas in the City; 3 = Establish factors involved in driving the epidemic in the city, through analysis of behavioural, biological, socio-economic and demographic data; 4 = Identify most-at-risk and priority population groups in the City Administration (sex workers, in-school youth, prisoners/inmates, discordant couples and IDUs); 5 = Quickly assess service availability, access and utilization for the identified most at risk/priority populations groups in the City Administration

\section{Results}

\section{Study characteristics}

The study includes characteristics such as the documents selected to be used in addressing the objectives and the findings in each document. The information relevant to the study in 41 documents was extracted and used accordingly as qualitative information as summarized in Table 1 , and quantitative in Table 2 and Figs. 2, 3, 4, 5, 6.

\section{HIV prevalences}

Surveys and assessment conducted in Addis Ababa such as EDHS [2, 5, 6], and EPHIA assessment [3] showed that prevalence of HIV is 4.7, 5.2, 3.4 and $3.1 \%$, respectively (Table 2). Around 104,851 PLHIV live in Addis Ababa contributing nearly to $17.7 \%$ of the PLHIV population in the country, while it contributes $3.5 \%$ to the total population of the country [1].

Prevalences of HIV in Addis Ababa from Antenatal care (ANC) based surveillance of 2005-2014 are in a range of lowest in 2012 (4.4\%) to the highest in 2005 (12.1\%). The prevalence is relatively higher in 2014 (5.5\%) than the prevalence in 2012 (4.4\%). In addition, the prevalence from prevention of mother to child (PMTCT) surveillance report of $2016(1.8 \%)$ is lower than the prevalence from ANC surveillance report of 2014 (Fig. 2).

Table 2 HIV prevalence in Addis Ababa from EDHS and EPHIA $[2,3,5,6]$

\begin{tabular}{|c|c|c|c|}
\hline \multirow[t]{2}{*}{ Studies } & \multicolumn{3}{|c|}{$\%$ HIV prevalence } \\
\hline & Total & Women & Men \\
\hline EDHS 2005 & 4.7 & 6.1 & 3.0 \\
\hline EDHS 2011 & 5.2 & 6.0 & 4.3 \\
\hline EDHS 2016 & 3.4 & 4.2 & 2.2 \\
\hline EPHIA 2017 & 3.1 & - & - \\
\hline
\end{tabular}

\section{Hotspot areas of HIV transmission}

The most common hot spots in Addis Ababa are areas where bars, groceries, pensions, guest houses, hotels, brothels, massage houses, khat houses, shisha houses, night clubs, drinking establishments and tourist frequented settings are concentrated. Condominiums are also mentioned as hotspot areas because sex workers commonly rent condos and are becoming centre of sexual transactions. There are various behavioural, biological and socio-economic predisposing risk factors that drive the epidemic in these hotspot areas in particular and the general population in general $[13,14]$.

\section{Factors involved in driving the epidemic Behavioural factors}

Low comprehensive knowledge about HIV/AIDS; alcohol and khat, shisha, substance abuse; gender based violence including rape; sex with multiple partners; practices of unsafe sex and inconsistent condom use; and dissatisfaction with sexual life in marriage are among major predisposing behavioural risk factors for the spread of HIV $[13,15,16]$. According to study conducted by OSSHD $72.5 \%$ of the intraveinous drug users (IDUs) in Addis Ababa had the habit of reusing needle and syringe [17]. In addition, early sexual debut, peer influence of young girls to engage in transactional sex, virginity selling, unfaithfulness for marriage, and boyfriend/ girlfriend sharing are identified as risk factors for HIV transmission $[13,15,18]$. In other studies, the percentage of men who had sex with non-marital, noncohabiting partners is highest in Addis Ababa (26\%) compared to national (16\%). In Addis Ababa, the highest mean number of lifetime sexual partners reported by men is 5.2 ; and $72.4 \%$ of women and $41.8 \%$ men reported using condom during last sexual intercourse with non-regular partner [2]. 
HIV prevalence in Addis Ababa, ANC 2005-2014 and PMTCT 2016

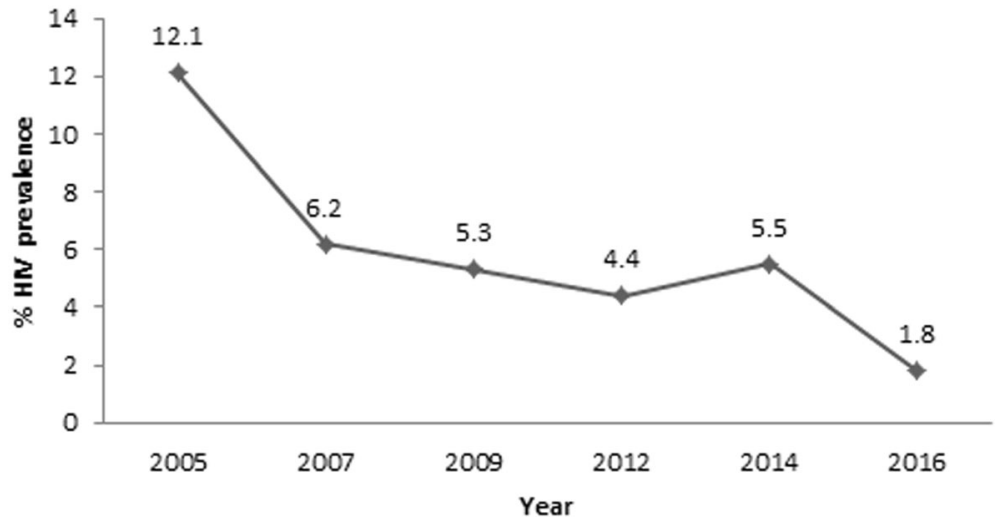

Fig. 2 HIV prevalence in Addis Ababa, ANC 2005-2014 and PMTCT 2016 [7-10]

\section{Biological factors}

Discordant couples have the highest risk of acquiring HIV. From the total HIV positive couples in Addis Ababa, $4.3 \%$ of them were found to be discordant [2]. The proportion of disclosure of HIV/AIDS diagnosis to HIV-infected children is low. Almost one in ten HIV exposed infants become HIV positive in Ethiopia. Two and $4 \%$ of the HIV exposed babies were HIV positive by 6 and 18 months, respectively [19]. There is low utilization of timely early infant diagnosis (EID) services. Being from the rural residence, home delivery, lack of understanding of the efficacy of ART, negative religious influences, and mixed infant feeding practices increased the risk of HIV transmission to children [20, 21].

\section{Socio-economic factors}

There are various socioeconomic factors contributing for high HIV epidemic in the City. High concentration of FSWs as means of livelihood; low socio-economic status; increasing sexual practices in massage houses; practice of intergenerational sex; high number of establishment like bars, hotels, restaurants, pastries, day and night clubs, brothels, pensions, local drink houses, and guest houses; engagement of gate-keepers, brokers and hotel owners in facilitating young girls to have transactional sex; growing number of construction and industry sites leading to increasing daily laborers from all parts of the country; living in groups to share house rent; high presence of movie houses that show pornographies; virtual appointments for dating and sexual relation; presence of naked dancing and call girls service; serving of the cosmetic and cloth shops for drugs distribution; increasing number of migration and visitors; cultural change and moral deterioration are the socioeconomoc predisposing risk factors. Similarly, absence of

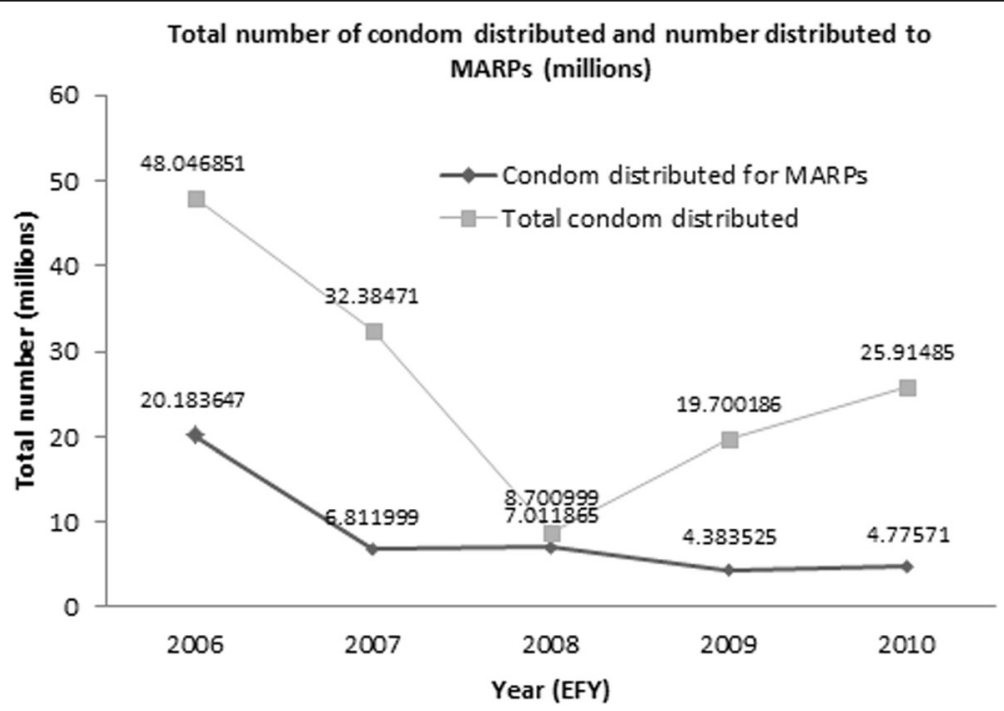

Fig. 3 Total condom distributed and condom distributed for MARPs from 2006 to 2010 EFY [11]. EFY=Ethiopian fiscal year 


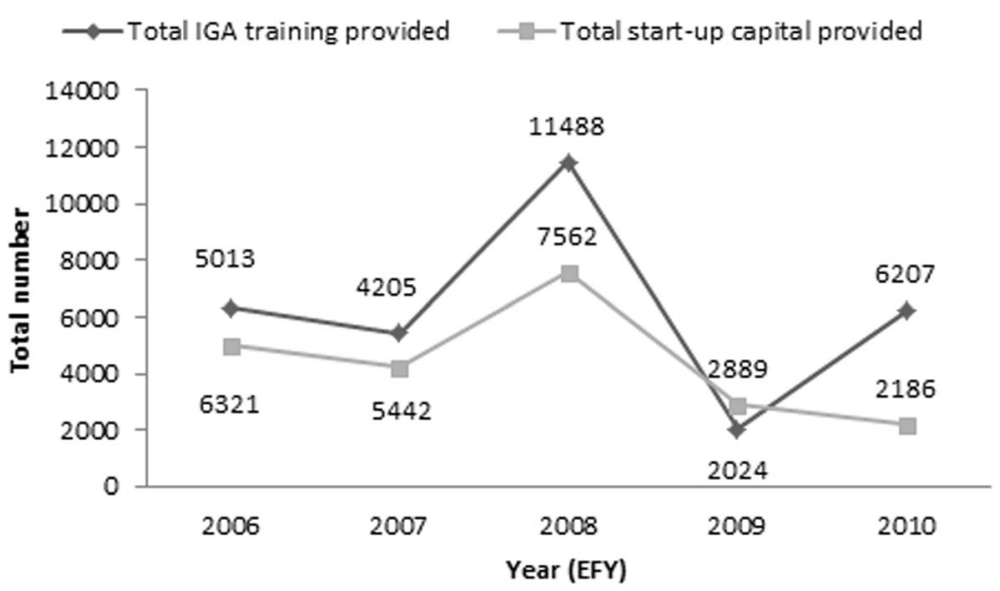

Fig. 4 Total number of individuals who were provided IGA training and start-up capital from 2006 to 2010 EFY; IGA = income generating activities [11]. EFY = Ethiopian fiscal year

recreational centers for youth, divorce and widowhood are aggravating factors for the spread of HIV in the City $[2,13,22]$.

\section{Key and priority populations}

MARPs Survey showed that the prevalence of HIV infection were $23 \%$ in self-identifying FSWs and $4.5 \%$ in truck drivers [23]; 4.2\% in prison settings [24] and 5.7\% HIV among mobile workers [14]. About $15.5 \%$ of drivers have misconceptions about HIV prevention methods [23]. According to recent estimates, there are about 200,000 FSWs in Ethiopia [25]. The majority of FSWs (57.5\%) are 24 years and younger, and about $14 \%$ are 19 years or younger [26]. MARPs study [23] also showed that the size of FSWs in Addis Ababa was estimated to be 10,267. HIV prevalence in FSWs is four times higher than the general population.

A total of 4068 IDUs are estimated to be located in Addis Ababa [27]. The majority (72.5\%) of the IDUs

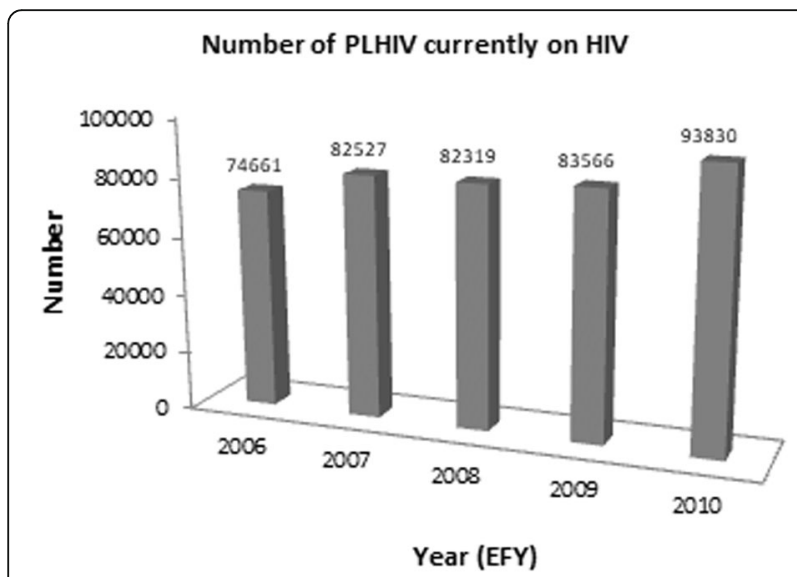

Fig. 5 Number of individuals currently on ART (cumulative), 2006$2011 \mathrm{EFY}$ [11]. EFY=Ethiopian fiscal year from Addis Ababa had the habit of reusing needle and syringe. Of the 177 Addis Ababa residents who claimed to have tested for HIV, 70 (39.5\%) disclosed as HIV positive [17]. In addition, the prevalence of HIV among IDUs in Addis Ababa is 6, and 40\% of IDUs reported ever-sharing needles. Furthermore, among HIV-positive IDUs, $60 \%$ reported sharing a needle the last time they injected [27]. Male IDUs are higher in number than female users at a ratio of $9: 1$ and 3/4 of the IDUs were below the age of 35 years [17].

In Addis Ababa, following on identifying FSWs as $\mathrm{KP}$, various priority populations were also identified. The priority populations (PPs) are divorced and widowed persons; HIV-negative partners in discordant couples; long-distance truckers and taxi drivers and their assistants; paying clients and non-paying ('Balukas') of sex workers; individual engaged in transactional sex including sugar daddies and mummies, and waitresses; daily labourers in constructions and factories; IDUs; brokers, managers and workers in bars, groceries, pensions, guest houses, hotels, local drink houses, massage houses and shisha houses; and vulnerable adolescents and youth (immigrants from all parts of the country, migration returnees, house maids, street children, high education institution students and night school students) $[13,15,25,28]$.

\section{HIV transmission interventions Behavioral interventions}

Behavioural change communication (BCC), conducting peer and outreach education sessions, transmitting messages using mini-media and mass-media, condom promotion, and life skill trainings are the common behavioural interventions. The national average performance of condom distribution to MARPs group is $43.9 \%$ of the plan while for Addis Ababa it was $28.9 \%$ of their 
\% AIDS related death in Addis Ababa, 2007-2011

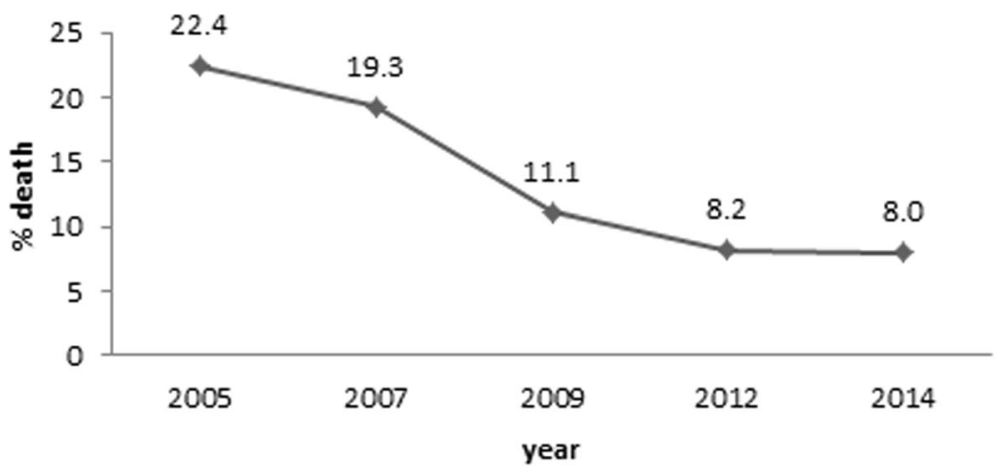

Fig. 6 Percentage of AIDS death in Addis Ababa from 2007 to 2011 [12]

plan that is far below the national average. Likewise, the proportion of condom distributed to MARPs is very low, only $18.4 \%$ of the total condom distributed in the city [29, 30, Fig. 3].

\section{Structural interventions}

Structural interventions aiming to reduce vulnerability or ensuring service accessibility are being implemented including provision of economic strengthening, mapping and identification of hotspot areas and risky target groups, drop-in-centres (DICs), gender based violence and referral linkage $[11,29]$. Findings indicated that economic strengthening interventions are diminishing in scale (Fig. 4).

\section{Biomedical interventions}

Biomedical interventions services are distribution of condom, HIV testing, sexually transmitted infection (STI) screening and treatment, ART, PMTCT and family planning, and ART post-exposure prophylaxis. In addition, ART pre-exposure prophylaxis for FSWs and discordant couples is at piloting stage. More than $10 \%$ of the BCC beneficiaries/FSWs had never been tested for HIV [26]. Some parents are refusing to give consent for their children to access HIV testing services (HTS) and ART services [30].

Behavioral, socio-economic and biomedical factors contributed to discontinuation ART. Heavy pill burden, fear of stigma and discrimination, cost and access to transportation, medication side effects, economic problems in the household, long travel due to distance from ART clinics, long waiting times, alcohol drinking, smoking, being with baseline $\mathrm{CD} 4<200$ cells $/ \mathrm{mm}^{3}$, having mental illness, being bed ridden functional status, and dissatisfaction with healthcare services were risk factors for ART discontinuation. Males were reported to be most affected by discontinuation from being away from home [31-34]. More than 6\% of HIV positive FSWs who started ART reported discontinuation of treatment for more than seven days in the three months prior to the assessment [26]. With the introduction of appointment spacing, some patients complain of lack of storage space for the six-month supply of ARTs, poor storage conditions for their medicines, and preference of frequent follow up. On the other hand, health workers are also concerned about adherence given the less frequent contact of PLHIV with the health services [35].

The HIV care and treatment service coverage indicated ART coverage is $74.6 \%$, and viral load testing coverage is about $60 \%$ with $87.5 \%$ viral suppression among those who received viral load testing [11]. The national average for the first, second and third 90's for urban Ethiopia is 72,71 and $70.1 \%$, respectively. VLS among 15-64 years of age HIV-positives in urban areas is close to the target (70.1\%) but varies by age, sex and region. VLS is distinctly lower at $48.2 \%$ in youth $15-24$ compared to the adult above 25 years of age. The status of the three 90's for Addis Ababa is below the national urban average. Status of the three 90's in Addis Ababa for the age group 0-64 years is lower than the national average which is: $65.2 \%$ for the 1 st $90,63.3 \%$ for the 2 nd 90 and $58.2 \%$ of all PLHIV had VLS with viral load level of $<1000$ copies/ml [3]. In Addis Ababa, the total number of clients on ART were 94,240 and 3616 were newly enrolled during the reporting period. The retention at 12 months was $87 \%$ [29, Fig. 5].

The Addis Ababa Mortality Surveillance Program using burial surveillance with verbal autopsy method [12] to identify AIDS and other causes of death showed that HIV/AIDS mortality is higher among females (12.1\%) as compared to males (9.5\%). In Addis Ababa from 2007 to 2010, an overall declining trends of AIDS related mortality was observed. However, starting 2010 onwards it seems stabilized (Fig. 6). 


\section{Discussion}

The current HIV program is applying targeted approaches so that both national and global targets are realized. In cognizant with that, Ethiopia has identified KPPs based on prevalence rate of specific groups and its respective context. The recognized KP group in Ethiopia is the FSWs. FSWs in Ethiopia are identified as KP in response to HIV epidemic as they are highly and consistently exposed to risky sexual practices which lead to HIV infection and transmission. Hence, evidence show that HIV prevalence among FSWs is the highest compared to other risk groups. The density of the FSWs population correlates closely with high PLHIV burden $[15,28,36]$. HIV transmission interventions include behavioural, biomedical and structural components. The current strategic plan intends to achieve the three 90 targets by 2020 through targeted social mobilization and HIV testing, linkage to care, quality of HIV treatment, and virtual elimination of MTCT, envisioning ending AIDS by 2030 [37].

There is relative decline of HIV prevalence from 2005 and 2016 EDHS findings in the city. However, antenatal clinic (ANC) based surveillance 2014 (5.5\%), and PMTCT 2016 (1.8\%) HIV prevalence [7] revealed that there is significant variation in reduction of HIV prevalence between the two study findings. Therefore, the comparison of the ANC and PMTCT surveillances findings needs cautious interpretation. There is need of implementing different behavioural, structural and biomedical transmission intervention measures on behavioural, biological and socio-economic factors that predisposed to HIV/AIDS in order to prevent and control rapid transmission. In connection to relatively better economic activities and social services, Addis Ababa attracts productive age groups from all over the country. Besides, the City serves as a gateway to the world. This also implies huge cultural exchange and dynamic and complex sexual behaviour, practices and networking catalysed by the presence of various types of sex workers [13]. There is sexual mixing of KPPs with the general population. The most affected populations are diluted by the general population. These serve as factors impacting the HIV transmission which call for a need to innovative HIV prevention and control strategies. Therefore, targeted activities need to be considered in designing strategies to promote testing and tracing HIV positives. Prevention and control measures should also be strengthened in the general population as well.

Combination ART acheives sustained HIV viral suppression and contributes to improvement in the quality of life, and reductions in mortality, progression to AIDS, opportunistic infections (OIs), hospitalization, and decreased HIV transmission to uninfected persons [38]. The stability of death by HIV/AIDS in Addis Ababa based on the studies [12] may be explained by better adherence follow-up and access for care and treatment.

Noncompliance to medical instruction and poor adherence fosters emergence of drug resistance. In addition, limited availability of laboratory services such as HIV RNA load and drug resistance testing and monitoring due to lack of experience of health professionals, and weak infrastructure and health care system contribute to delay in diagnosis of treatment failure [39, 40]. The high rate of transmitted and preexisting drug resistance mutations in Ethiopian patients are identified [41]. The finding of HIV-positives with high viral load in some studies [3] alarms the presence of people with high viral load which increases the risk of HIV transmission in the community.

There are gaps and challenges of HIV/AIDS prevention and control in Addis Ababa. Some of the gaps and challenges are weak monitoring of the quality of interventions, less emphasis in prevention, limited linkage of positive clients, lost to follow up, long turnaround time of viral load (VL) and EID tests, limited index-casetestings, limited effort in preventing substance abuse, inconsistent supply of test kits and condom, financial shortage, limited manpower and coordination, data quality problem, and gap in use of program data or research findings. Therefore, those challenges should be solved in order to achieve the three 90's.

Developing appropriate service package, implement targeted intervention emphasizing on primary prevention; update existing implementation manuals to address the current situations and emerging vulnerability factors; create awareness to and engage hotel, bar, night clubs, pension, etc. owners and managers and police officers to play a key role in HIV prevention; ensuring availability of condom for KPPs including during the night time; strengthen a mechanism to work with media; promote open discussion about sexual and reproductive health; ensure availability and accessibility of commodities like ARTs, test kits and condoms; strengthen targeted testing to enhance identification of new cases and linking them to care and treatment services; ensuring effective implementation of legal framework governing massage houses, drug uses, shisha and khat houses as well as illegal brokers and rehabilitation of IDU are required. In order to implement these recommendations, gaps in critical enablers such as social mobilization, coordination, political commitment, resource, partnership, monitoring and evaluation, and data quality have to be addressed.

The limitations of this systematic review were the bad data quality in most works, and limitations of the quantitative secondary information due to their own inherent design and personal errors. Collection of secondary quantitative data was tried for many variables; however, interpretable data were found only for presented 
variables. In addition, due to many documents excluded and done by myself only, there may be bias and a chance of missing relevant information to be analyzed.

\section{Conclusions}

Generally, even if the HIV prevalence is stabilized, the prevalence varies along different groups of the population within socio-demographic factors. There are many behavioural, biological and socio-economic factors that predisposed to HIV/AIDS. In addition, behavioural, structural and biomedical transmission intervention mechanisms are also affected by finance and lack of skilled man-power. Therefore, implementing targeted intervention focusing on primary prevention; update existing manuals and materials to address the current situations; ensuring availability of ARTs, test kits and condoms; broadcast key HIV messages on selected outlets; promote open discussion about sexual and reproductive health; strengthen targeted testing through index-case-testing, case-based-surveillance and social-network-strategy (SNS) to reach undiagnosed and new HIV infected people and linking them to care and treatment services; ensuring legal framework of governing massage houses, drug uses, shisha and khat houses, as well as illegal brokers are recommended in order to solve these challenges and fill the gaps. If it is able to accomplish these activities with plan in collaboration with partners, there will be bright future prospect to accomplish the three 90's as planned.

\begin{abstract}
Abberviations
AAHAPCO: Addis Ababa HIV/AIDS Prevention and Control Office; AAHB: Addis Ababa Health Bureau.; ANC: Antenatal clinic; ART: Antiretroviral therapy; BCC: Behavioural change communication; CBS: Case based surveillance; CDC: Americal Centre for Diseases Control and Prevention:; CSA: Central Statistical Agency; DICs: Drop-in-centres; EDHS: Ethiopian demographic and health survey.; EFY: Ethiopian fiscal year; EID: Early infant diagnosis; EPHA: Ethiopian Public Health Association; EPHI: Ethiopian Public Health Institute; EPHIA: Ethiopian population based HIV impact assessment; FHAPCO: Federal HIV/AIDS Prevention and Control Office; FMOE: Federal Ministry of Education; FMOH: Federal Ministry of Health; FSWs: Female sex workers.; HAART: Highly active antiretroviral therapy; HTS: HIV testing services; ICT: Index case testing; IDUs: Intraveinous drug users; IGA: Income generating activities.; KP: Key population; KPP: Key and priority population; MARPs: Most at risk populations; MTCT: Mother-to-Child-Transmission; Ols: Opportunistic infections.; OSSHD: Organization for Social Services, Health and Development; PEPFAR: President's Emergency Plan for AIDS Relief; PITC: Professional initiated testing and counseling; PLHIV: People Living With HIV; PMTCT: Prevention of Mother to Child transmission; PNS: Partner notofication services; PP: Priority population; PPs: Priority populations; PSI/ E: Population Services International, Ethiopia; SNNP: Sothern Nations, Nationalities and Peoples; SNS: Social networking strategy; STI: Sexually transmitted infections; UNODC: United Nations Office on Drug and Crime; VL: Viral load; VLS: Viral load suppression; WHO: World Health Organization
\end{abstract}

\section{Acknowledgements}

I acknowledge all individuals, institutions and organizations who contribute in making the documents available to this review directly or indirectly.

\section{Author's contributions}

MA involved in the conceptualization, document collection, methodology, writing original draft, and editing of the draft to final manuscript. The author read and approved the final manuscript.

\section{Funding}

No funding was obtained for this study.

\section{Availability of data and materials}

This paper is a systematic review of previously published data. All data generated or analysed during this study are included in this published article.

Ethics approval and consent to participate

Not applicable.

\section{Consent for publication}

Not applicable.

\section{Competing interests}

The author declares that he/she has no competing interests.

Received: 5 August 2019 Accepted: 1 November 2019

Published online: 21 November 2019

\section{References}

1. Ethiopian Public Health Institute (EPHI). HIV Related Estimates and Projections for Ethiopia. Addis Ababa. Ethiopia. March 2018a.

2. Central Statistical Agency (CSA) [Ethiopia] and ICF International. Ethiopia Demographic and Health Survey 2016: HIV Report. Addis Ababa, Ethiopia, and Rockville, Maryland, USA.

3. Ethiopian Public Health Institute (EPHI). Ethiopian population-based HIV impact assessment (EPHIA). Addis Ababa. Ethiopia. August 2018b.

4. Moher D, Shamseer L, Clarke M, Ghersi D, Liberati A, Petticrew M, Shekelle P, Stewart LA. Preferred reporting items for systematic review and metaanalysis protocols (PRISMA-P) 2015 statement. Systematic reviews. 2015;4:1.

5. Central Statistical Agency (CSA) [Ethiopia] and ORC Macro. Ethiopia Demographic and Health Survey. Addis Ababa, Ethiopia, and Calverton. USA: Maryland; 2005.

6. Central Statistical Agency (CSA) [Ethiopia] and ICF International. Ethiopia Demographic and Health Survey. Addis Ababa, Ethiopia, and Calverton. USA: Maryland; 2011.

7. Ethiopian Public Health Institute (EPHI). Report on the 2014 round antenatal care sentinel HIV surveillance in Ethiopia. Addis Ababa. Ethiopia. July 2015.

8. Ethiopian Public Health Institute (EPHI). Report on the 2009 round antenatal care sentinel HIV surveillance in Ethiopia. Addis Ababa. Ethiopia. August 2011.

9. Ethiopian Public Health Institute (EPHI). Report on the 2012 round antenatal care sentinel HIV surveillance in Ethiopia, February 2014, Addis Ababa, Ethiopia.

10. Ethiopian Public Health Institute (EPHI). Round PMTCT based HIV sentinel surveillance in Ethiopia technical report, December 2017. Ethiopia: Addis Ababa; 2016.

11. Federal HIV/AIDS Prevention and Control Office (FHAPCO). Annual multisectoral response performance report, Addis Ababa, Ethiopia, 2018.

12. Ethiopian Public Health Association (EPHA) and American Disease Control and Prevention (CDC). Causes of Death in Addis Ababa Mortality Surveillance Program from. Verbal autopsy method: Addis Ababa mortality surveillance program (AAMSP), College of Health Sciences, Addis Ababa University. March. 2007-2011;29:2012.

13. Addis Ababa HIV/AIDS Prevention and Control Office (AAHAPCO) Epidemiological Synthesis on HIV/AIDS in Addis Ababa City Administration, Addis Ababa City Administration HIV/AIDS Prevention and Control Office/ Health Bureau in collaboration with School of Public Health, Addis Ababa University, Addis Ababa, Ethiopia, December 2017.

14. Lakew Y, Benedict S, Haile D. Social determinants of HIV infection, hotspot areas and subpopulation groups in Ethiopia: evidence from the National Demographic and health survey in 2011. BMJ. 2015;5:e008669.

15. Federal Ministry of Education (FMOE). Education Sector Response to HIV and AIDS: Learning from good practices in Ethiopia, April 2012.

16. Population Services international, Ethiopia (PSI/E). Socio-Demographic and Mobility Profile of MULU/MARPs BCC and Post-test Club Beneficiaries, year of publication not known.

17. Deyessa N, Senbate B, Abdo A, Yusuf I, Chaffo D, Mundia BM, et al. Population Estimation and Rapid Situational Assessment on Harm Reduction and HIV Prevention among People Who Inject Drugs in Hawassa and Addis Ababa. Department of Preventive Medicine, School of Public Health, College of Health Sciences, Addis Ababa University; Organization for Social Services, Health and Development (OSSHD); Kenya AIDS Non-Governments Consortium (KANCO), 
Nairobi, Kenya; and London School of Hygiene and Tropical Medicine; Addis Ababa City Administration Health Bureau (AAHB). Performance report for the year 2010 EFY. Addis Ababa, 2017.

18. Cherie A, Berhane Y. Peer pressure is the prime driver of risky sexual behaviors among school adolescents in Addis Ababa. Ethiopia World Journal of AIDS. 2012;2:159-64.

19. Mirkuzie AH. Implementation and outcomes of guideline revisions for the prevention of mother-to-child HIV transmission in mother support Programme, Addis Ababa. Ethiopia PLoS ONE. 2018;13:e0198438.

20. Klaus K, Baldwin J, Izurieta R, Naik E, Seme A, Corvin J, et al. Reducing PMTCT attrition: perspectives of HIV+ women on the prevention of motherto-child HIV Services in Addis Ababa. Ethiopia Ethiop Med J. 2015;53:91-104.

21. Endalamaw A, Demsie A, Eshetie S, Habtewold TD. A systematic review and meta-analysis of vertical transmission route of HIV in Ethiopia. BMC Infect Dis. 2018:18:283.

22. Menna T, Ali A, Worku A. Prevalence of "HIV/AIDS related" parental death and its association with sexual behavior of secondary school youth in Addis Ababa. Ethiopia: a cross sectional study BMC Public Health. 2014;14:1120.

23. Ethiopian Public Health Association (EPHA), American Disease Control and Prevention (CDC), Ethiopian Public Health Institute (EPHI) and Federal HIV/ AIDS Prevention and Control Office (FHAPCO). Ethiopian National Key Population HIV Bio-behavioral Surveillance Round I, 2013 Report.

24. UNODC and Prison Adminstration. Rapid assessmnet of HIV in prision settings, 2014.

25. President's Emergency Plan for AIDS Relief (PEPFAR). Ethiopia Country Operational Plan (COP/ROP), Strategic Direction Summary, May 17, 2018.

26. Population Services international. Ethiopia (PSI/E). Reaserch Brief: Exploring barriers and motivators for using HIV prevention services among transactional sex workers in Ethiopia; 2016.

27. Demissie M, Johnston LG, Muleta M, Desyebelew D, Belete W. G/Egxiabehre $a$, et al. prevalence of HIV and other infections and injection behaviours among people who inject drugs in Addis Ababa, Ethiopia. Afr J AIDS Res. 2018;17:259-64.

28. Federal HIV/AIDS Prevention and Control Office (FHAPCO). HIV Prevention in Ethiopia, National Roadmap 2018-2020, November 2018.

29. Federal Ministry of Health (FMOH). DHIS II Report, Addis Ababa, Ethiopia, 2018.

30. Biadgilign S, Deribew A, Amberbir A, Escudero HR, Deribe K. Factors associated with HIV/AIDS diagnostic disclosure to HIV infected children receivingHAART: a multi-center study in Addis Ababa. Ethiopia PloS One. 2011;6:e17572.

31. Gesesew HA, Mwanri L, Ward P, Woldemicahel K, Feyissa GT. Factors associated with discontinuation of anti-retroviral therapy among adults. JBI Database of Systematic Reviews \& Implementation Reports. 2016;14:26-37.

32. Gesesew HA, Ward P, Hajito KW, Feyissa GT, Mohammadi L, Mwanri L. Discontinuation from antiretroviral therapy: a continuing challenge among adults in HIV care inEthiopia: a systematic review and meta-analysis. PLoS One. 2017a;12:e0169651.

33. Gesesew HA, Ward P, Woldemichael K, Mwanri L. Prevalence, trend and risk factors for antiretroviral therapy discontinuation among HIV-infected adults in Ethiopia in 2003-2015. PLoSONE. 2017b;12:e0179533.

34. Bezabhe WM, Chalmers L, Bereznicki LR, Peterson GM, Bimirew MA, Kassie DM. Barriers and facilitators of adherence to antiretroviral drug therapy and retention in care among adult HIV-positive patients: a qualitative study from Ethiopia. PLoS One. 2014;9:e97353.

35. Tiruneh $\mathrm{YM}$, Wilson IB. What time is it? Adherence to antiretroviral therapy in Ethiopia. AIDS Behav. 2016:20:2662-73.

36. President's Emergency Plan for AIDS Relief (PEPFAR). PEPFAR Country/ Regional Operational Plan (COP/ROP). Guidance (Draft), December 30, 2016.

37. Federal HIV/AIDS Prevention and Control Office (FHAPCO). HIV/AIDS Strategic Plan 2015-2020 in an Investment Case Approach, Addis Ababa, Ethiopia, 2014

38. Gudina EK, Teklu AM, Berhan A, Gebreegziabhier A, Seyoum T, Nega A, Medhin G, Kebede A, Assefa Y. Magnitude of antiretroviral drug toxicity in adult HIV patients in Ethiopian: a cohort study at seven teaching hospitals. Ethiop J Health Sci. 2017;27:3952

39. Misgena DK. The pattern of immunologic and virologic responses to highly active antiretroviral treatment (HAART): does success bring further challenges? Ethiop J Health Dev. 2011;25:61-7.

40. Bernabas G, Sibhatu MK, Berhanel Y. Antiretroviral therapy program in Ethiopia benefits from virology treatment monitoring. Ethiop J Health Sci. 2017;27:1-2
41. Telele NF, Kalu AW, Gebre-Selassie S, Fekade D, Abdurahman S, Marrone G, et al. Pretreatment drug resistance in a large countrywide Ethiopian HIV-1C cohort: a comparison of sanger and high-throughput sequencing. Sci Rep. 2018:8:7556.

\section{Publisher's Note}

Springer Nature remains neutral with regard to jurisdictional claims in published maps and institutional affiliations.

\section{Ready to submit your research? Choose BMC and benefit from:}

- fast, convenient online submission

- thorough peer review by experienced researchers in your field

- rapid publication on acceptance

- support for research data, including large and complex data types

- gold Open Access which fosters wider collaboration and increased citations

- maximum visibility for your research: over $100 \mathrm{M}$ website views per year

At BMC, research is always in progress.

Learn more biomedcentral.com/submissions 